\title{
Frequency and severity of retinopathy of prematurity in a neonatal intensive care unit
}

\author{
Heladia García, Héctor González-Cabello, Carlos Augusto Soriano-Beltrán, Marco Antonio Soto-Dávila, \\ Yolanda Vázquez-Lara and Claudia Hernández-Galván \\ Instituto Mexicano del Seguro Social, Centro Médico Nacional Siglo XXI, Evidence Analysis and Synthesis Research Unit, Pediatrics Hospital, \\ Ciudad de México, Mexico
}

\begin{abstract}
Introduction: Retinopathy of prematurity (ROP) is a disease where retinal blood vessels do not develop normally and may cause visual damage and blindness. Objective: To determine the frequency and severity of ROP in preterm newborns. Method: A descriptive, comparative study was carried out within the 2009-2013 period. Patients' general characteristics were recorded, including gestational age and postmenstrual age at the moment of ophthalmologic examination, as well as ROP severity and type of treatment. Results: $A$ total of 326 preterm newborns were included: $47.8 \%(n=156)$ had ROP; in $21.1 \%$ it was severe (stage $\geq 3$ ). Median gestational age was 28 weeks in preterm newborns with ROP, median birth weight was $1000 \mathrm{~g}$, and median postmenstrual age at ophthalmological examination was 36 weeks. Of the infants with ROP, $71.1 \%$ received treatment: $63.4 \%$ of those who had mild ROP and $100 \%$ of those with severe ROP. Conclusions: ROP frequency was high, higher than that reported in developed countries and similar to that in developing countries. The frequency of severe ROP was also higher. It is necessary for effective programs for the detection and opportune treatment of ROP to be established.
\end{abstract}

KEY WORDS: Retinopathy of prematurity. Preterm neonate. Photocoagulation.

\section{Introduction}

Retinopathy of prematurity (ROP) is a fibro- and vasoproliferative peripheral vitreoretinopathy that occurs in premature newborns (NB) undergoing oxygen therapy, the etiopathogenesis of which is still unknown. ${ }^{1}$ It was described by Terry ${ }^{2}$ in 1942 as retrolental fibroplasia. In 1951, Heath named it retinopathy of prematurity. ${ }^{3}$ ROP is the most common cause of childhood blindness in developed and developing countries. ${ }^{1,4}$ Advances in neonatal intensive care have increased extremely low birth weight (ELBW) premature infants survival and, therefore, the number of children at risk for developing severe ROP has also increased. ${ }^{5}$

In the 1950's, Kinsey ${ }^{6}$ reported the first ROP epidemic and associated it with oxygen therapy, which led to restrict its use. In the decade of the 80 's, a second epidemic occurred: ${ }^{7}$ currently, the third one is considered to be occurring.

The incidence of ROP and its serious modality has shown different trends. In 1956, the CRYO-ROP group reported an incidence of $27 \%$, while in a 1986 and 1987 multi-center study, an increase of $65.8 \%$ was reported in premature NBs with $<1251 \mathrm{~g}$ weight and $81.6 \%$ in premature infants with body weight $<1000 \mathrm{~g} .{ }^{9}$ However, between 1995 and 1996, an incidence decrease to $41.3 \%$ was reported in this same group. ${ }^{10}$

The ETROP group, between 2000 and 2002, reported an incidence of $68 \%$, similar to that reported by the CRYO-ROP group in 1986 and 1987., 11

The ROP incidence reported in developed countries is highly variable: it ranges from 9.3 to $68 \%$. $^{12-17}$

There are only few reports on the incidence of ROP in Mexico. In the studies that have been carried out in different centers it ranges from 13.3 to $30 \%{ }^{18-21}$
Date of reception: 25-01-2018

Date of acceptance: 18-07-2018

DOI://dx.doi.org/10.24875/GMM.M18000190
Gac Med Mex. 2018;154:475-481

Contents available at PubMed www.gacetamedicademexico.com 
Screening for ROP early detection is considered to be a priority since $1988 .{ }^{5}$ The main purpose of screening is to identify all premature infants that require treatment for ROP or tighter ophthalmological follow-up, as specified in the latest recommendations established by the American Academy of Pediatrics, the American Association of Pediatric Ophthalmology and Strabismus and the American Academy of Ophthalmology. ${ }^{22}$

The recommendations for screening are the following: birth weight $\leq 1500 \mathrm{~g}$ or gestational age $\leq 32$ weeks; it should be carried out by an ophthalmologist with experience in the evaluation of premature children, between weeks 4 and 6 of chronological age, or between weeks 31 and 33 of postconceptional age; successive evaluations will be determined based on the findings of the first ophthalmologic examination. ${ }^{22}$

A significant number of children who develop severe ROP will have visual $(14.5 \%)$ and structural $(9.1 \%)$ unfavorable results in spite of ablative treatment with laser or cryotherapy. ${ }^{23,24}$

The purpose of the present study was to identify the frequency and severity of ROP, as well as the administered treatment in premature NBs who were admitted to the neonatal intensive care unit (NICU) or who were provided care to at the outpatient ophthalmology clinic of a tertiary care hospital.

\section{Method}

Descriptive, comparative study of patients admitted to the NICU and to the Ophthalmology Outpatient Clinic of the Pediatrics Hospital of Centro Médico Nacional Siglo XXI, Instituto Mexicano del Seguro Social, Mexico City, where patients referred from other hospital units of the southern area of Mexico City, some states of the Mexican Republic and private hospitals are cared for. The protocol was approved by the Local Research and Ethics Committee of the hospital where the research was conducted.

Premature NBs with gestational age $\leq 32$ weeks at birth or birth weight $\leq 1500 \mathrm{~g}$, chronological age $\geq 4$ weeks, who received supplementary oxygen and who were admitted to the NICU or were looked after at the ophthalmology outpatient clinic within the 2009-2013 period were included.

The following data were recorded: gestational age, birth weight, gender, Apgar score at 1 and 5 minutes, type of delivery, comorbidity, use of prenatal steroids, exogenous surfactant and supplementary oxygen, chronological age and postconceptional age at the time of ophthalmologic evaluation, ROP classification and severity and administered treatment.
ROP international classification was used, ${ }^{25}$ which groups it into 5 stages and 3 zones. In addition, whether there was plus disease (venous dilation, arteriolar tortuosity and posterior pole hemorrhages) was recorded. Severity was stratified in 2 categories: Mild ROP, comprising stages 1 and 2, and serious $\mathrm{ROP}$, which comprises stages 3,4 and $5 .{ }^{26}$

NBs who met the inclusion criteria were examined and treated by ophthalmologists of the hospital unit. Two investigators collected first assessment and follow-up data from the medical records.

\section{Statistical analysis}

Descriptive statistics was used; for qualitative variables, simple frequencies and percentages were calculated, and for quantitative variables, medians and intervals, since most variables did not follow a normal-like distribution.

For comparative analysis, two groups were formed: children with and without ROP. For the comparison of some variables, the chi-square test or Fisher's exact test were used for qualitative variables, and Mann-Whitney's U-test for the quantitative ones.

For the database generation and statistical analysis, the statistical program SPSS, version 17, was used.

\section{Results}

Three hundred and twenty-six NBs were included between January 2009 and December 2013: 156 children with ROP and 170 without ROP. Table 1 shows the general characteristics of the NBs of each group; both gestational age and birth weight were lower in children with ROP. Oxygen usage time was longer in the children with ROP $(p=0.0001)$. Surfactant was used more often in NBs who developed ROP ( $p=0.001)$. There was no difference between groups in postconceptional age at the moment of ophthalmologic examination, gender, type of delivery or prenatal steroid administration.

Table 2 describes the chronological age and postconceptional age at which the NBs were evaluated for the first time. The international recommendation on the ideal moment to perform the first ophthalmological examination is also shown.

Seventy-tree percent of children who did not develop ROP had their first ophthalmologic evaluation performed between weeks 4 and 6 of chronological age. Of total patients with ROP, $40.4 \%$ were examined between weeks 4 and 6 of chronological age, and only 
García $\mathrm{H}$, et al.: ROP frequency in premature NBs

Table 1. Characteristics of newborns with retinopathy of prematurity

\begin{tabular}{|c|c|c|c|c|c|}
\hline \multirow[t]{2}{*}{ Variable } & \multicolumn{2}{|c|}{ With ROP $(n=156)$} & \multicolumn{2}{|c|}{ No ROP $(n=170)$} & $p^{*}$ \\
\hline & \multicolumn{2}{|c|}{ Median (interval) } & \multicolumn{2}{|c|}{ Median (interval) } & $\stackrel{\infty}{\leftarrow}$ \\
\hline Gestational age & \multicolumn{2}{|c|}{$28(24-34)$} & \multicolumn{2}{|c|}{$30(23-35)$} & $<0.0001$ \\
\hline Birth weight $(g)$ & \multicolumn{2}{|c|}{$1000(465-2290)$} & \multicolumn{2}{|c|}{$1260(370-1775)$} & $<0.0001$ \\
\hline 1-minute Apgar & \multicolumn{2}{|c|}{$6(0-8)$} & \multicolumn{2}{|c|}{$6(2-9)$} & $\frac{E}{d} \mathrm{~ns}$ \\
\hline 5-minute Apgar & \multicolumn{2}{|c|}{$7(2-9)$} & \multicolumn{2}{|c|}{$8(2-9)$} & (c) ns \\
\hline Age at admission (days) & \multicolumn{2}{|c|}{$47(1-154)$} & \multicolumn{2}{|c|}{$35(1-150)$} & $<0.0001$ \\
\hline Chronological age at ophthalmologic examination (weeks) & \multicolumn{2}{|c|}{$8(2-22)$} & \multicolumn{2}{|c|}{$6(3-21)$} & $\leq 0.001$ \\
\hline $\mathrm{PCA}^{£}$ at examination (weeks) & \multicolumn{2}{|c|}{$36(30-52)$} & \multicolumn{2}{|c|}{$36(30-51)$} & $\overline{\mathrm{O}} \mathrm{ns}$ \\
\hline \multirow[t]{2}{*}{ Time of $\mathrm{O}_{2}$ use (days) } & \multicolumn{2}{|c|}{$48(2-135)$} & \multicolumn{2}{|c|}{$35(3-98)$} & $<0.0001$ \\
\hline & 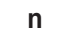 & $\%$ & $\mathrm{n}$ & $\%$ & 4 \\
\hline \multicolumn{5}{|l|}{ Gender } & 으 \\
\hline Male & 80 & 76 & 97 & 57.1 & $n s^{* *}$ \\
\hline Female & 51.3 & 48.7 & 73 & 42.9 & $\underline{\varepsilon}$ \\
\hline \multicolumn{5}{|l|}{ Type of delivery } & \\
\hline Vaginal & 29 & 18.6 & 36 & 21.2 & ens** \\
\hline Cesarean section & 127 & 81.4 & 134 & 78.8 & \pm \\
\hline Prenatal steroid & 102 & 65.4 & 110 & 64.7 & $n s^{\star *}$ \\
\hline Surfactant & 147 & 94.2 & 139 & 81.8 & $0.001^{* *}$ \\
\hline \multicolumn{5}{|l|}{$\begin{array}{l}{ }^{*} \text { Mann-Whitney U-test. } \\
{ }^{* \star} \text { Mantel-Haenszel Chi-square test. } \\
\text { EPCE = postconceptional age, ROP = retinopathy of prematurity, ns = not significant. }\end{array}$} & 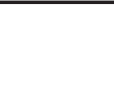 \\
\hline
\end{tabular}

Table 2. Relationship between gestational age at birth and age at ophthalmologic examination

\begin{tabular}{|c|c|c|c|c|}
\hline \multirow[t]{2}{*}{ Gestational age at birth, weeks } & \multicolumn{2}{|c|}{$\begin{array}{c}\text { American Academy of Pediatrics recommendations }{ }^{22} \\
\text { Age at first examination (weeks) }\end{array}$} & \multicolumn{2}{|c|}{$\begin{array}{c}\text { HP CMN SXXI } \\
\text { Age at first examination (weeks)* }\end{array}$} \\
\hline & Postconceptional & Chronological & Postconceptional & Chronologica \\
\hline $22^{\varepsilon}(0)$ & 31 & 9 & - & 2 \\
\hline $23^{£}(1)$ & 31 & 8 & 28 & 5 \\
\hline $24(1)$ & 31 & 7 & 36 & 12 \\
\hline $25(4)$ & 31 & 6 & $31-41$ & $6-16$ \\
\hline $26(22)$ & 31 & 5 & $30-43$ & $4-17$ \\
\hline $27(41)$ & 31 & 4 & $31-44$ & $4-17$ \\
\hline $28(62)$ & 32 & 4 & $32-45$ & $4-17$ \\
\hline $29(38)$ & 33 & 4 & $33-44$ & $4-13$ \\
\hline $30(70)$ & 34 & 4 & $34-52$ & $4-22$ \\
\hline $31^{\ddagger}(11)$ & 35 & 4 & $34-39$ & $3-8$ \\
\hline $32^{\ddagger}(50)$ & 36 & 4 & $36-42$ & $4-10$ \\
\hline $33(12)$ & - & - & $37-42$ & $4-9$ \\
\hline $34(11)$ & - & - & $38-41$ & 4-7 \\
\hline 35 (3) & - & - & $39-40$ & $4-5$ \\
\hline
\end{tabular}

IThis recommendation should be considered tentative rather than evidence-based, owing to the small number of survivors at this age.
\#lf necessary. 
Table 3. Retinopathy of prematurity frequency according to the international classification

\begin{tabular}{|c|c|c|c|c|c|c|c|c|}
\hline \multirow[t]{3}{*}{ Stage } & \multicolumn{6}{|c|}{ Zone } & \multicolumn{2}{|c|}{ Total } \\
\hline & \multicolumn{2}{|c|}{ I } & \multicolumn{2}{|c|}{ II } & \multicolumn{2}{|c|}{ III } & \multirow[b]{2}{*}{$\mathrm{n}$} & \multirow[b]{2}{*}{$\%$} \\
\hline & $\mathrm{n}$ & $\%$ & $\mathrm{n}$ & $\%$ & $\mathrm{n}$ & $\%$ & & \\
\hline 1 & 2 & 1.3 & 15 & 9.6 & 63 & 40.4 & 80 & 51.3 \\
\hline 2 & 1 & 0.6 & 20 & 12.8 & 22 & 14.1 & 43 & 27.6 \\
\hline 3 & 2 & 1.3 & 16 & 10.3 & 15 & 9.6 & 33 & 21.1 \\
\hline Total & 5 & 3.2 & 51 & 32.7 & 100 & 64.1 & 156 & 100 \\
\hline \multicolumn{9}{|c|}{ Plus disease } \\
\hline Stage I & 0 & 0 & 4 & 2.5 & 1 & 0.6 & 5 & 3.2 \\
\hline Stage II & 0 & 0 & 7 & 4.5 & 8 & 5.1 & 15 & 9.6 \\
\hline Stage III & 2 & 1.3 & 13 & 8.3 & 8 & 5.1 & 23 & 14.7 \\
\hline Total & 2 & 1.3 & 24 & 5.3 & 17 & 10.8 & 43 & 27.5 \\
\hline
\end{tabular}

Eleven patients developed retinopathy of prematurity in a single eye.

$4.4 \%$ of children with severe ROP were assessed at that age.

Most NBs had more than one associated disease. Bronchopulmonary dysplasia, patent ductus arteriosus, intraventricular hemorrhage and seizures were more common in the children with

ROP $(p<0.05)$. ROP frequency was $47.8 \%(n=156 / 326)$. In 145 patients, ROP was detected in both eyes and in 11 it was unilateral.

With regard to severity, $79.9 \%$ had mild ROP, in $21.1 \%$ it was severe and $27.5 \%$ had disease plus. Stage of the disease and affected area are described in table 3; most patients had ROP at stages 1 and 2 and in zones II and III; none had stage 4 or 5 ROP.

Figure 1 shows the relationship between gestational age and ROP frequency and severity. The highest frequency $(27.6 \%)$ occurred in NBs with gestational age between 27 and 29 weeks; in this age group, the frequency of severe ROP was also higher (63.6\%).

As regards birth weight, ROP was more common in those who weighed between 751 and $1000 \mathrm{~g}$ (19\%); in that weight category, the proportion of severe ROP was also higher (60.6 \%) (Fig. 2).

Patients who developed ROP had longer duration of oxygen supply; however, oxygen saturations that were used in these patients could not be determined because they all had been referred from other hospital units (Fig. 3).

Among the NBs with ROP, $71.1 \%(111 / 156)$ received treatment: $63.4 \%$ of those with mild ROP and $100 \%$ of NBs with severe ROP. In $43.9 \%$ (54/123) of the children with mild ROP, only paraocular dexamethasone was administered $(100 \mu \mathrm{g} / \mathrm{kg} / \mathrm{dose})$, in $19.5 \%(24 / 123)$, cryotherapy, laser photocoagulation or a combination thereof, in addition, paraocular steroid was used in 21 of these NBs. In $36.4 \%(12 / 33)$ of NBs with severe ROP, steroid and cryotherapy were administered; in $27.3 \%(9 / 33)$, cryotherapy, in $27.3 \%(9 / 33)$, laser and paraocular steroid, and in $9 \%(3 / 33)$, only laser.

Of total included patients, $67(20.5 \%)$ underwent a second evaluation. The interval between both evaluations had a median of 16 days (range of 5 to 69 days). Of these children, $23(34.3 \%)$ had ROP progression, $25(37.3 \%)$ had regression and 19 (28.4\%) were found with no changes. Of the 15 patients who in the initial evaluation had retinal immaturity, 9 had progressed to ROP, 3 improved and 3 remained equal, i.e., with immaturity, in the second evaluation.

\section{Discussion}

ROP is an alteration in the development of the retina in premature NBs with low birth-weight that potentially causes blindness in a low but significant percentage. In full-term children, the retina is fully developed, so ROP does not occur in them; however, in premature NBs, retinal development is incomplete, and the degree of retinal immaturity depends mainly on the NB degree of prematurity. ${ }^{22}$

The frequency of ROP in this study was high in comparison with that reported in some developed countries ${ }^{12,14,16}$ (although the VOND neonatal network reported $57 \%,{ }^{13}$ although it is within the range reported in Latin American countries, which ranges from 6.6 to $82 \%,{ }^{27}$ it was also similar to that of countries with scarce development such as Saudi Arabia, where $56 \%$ is reported. ${ }^{28}$ In Mexico, ROP frequency records are scarce, in addition to inclusion criteria being diverse. ${ }^{18-21}$

The risk for developing ROP is not only determined by prematurity and low birth weight, but by other factors such as patient severity status during his/her stay in the NICU, comorbidity and the procedures they undergo there, i.e., patients managed at each hospital unit are different, which makes it difficult to compare the incidence rates between different institutions and even more so between different countries, especially developed ones, where there are well-established ROP detection policies ${ }^{18,20,21}$

The frequency of severe ROP was $21.1 \%$, which is also higher than that reported. ${ }^{29}$ In Spain, an incidence of $15.6 \%{ }^{17}$ was recorded, while in the Netherlands it was $1.2 \% .^{11}$ In this study, it was similar to that recorded in Latin American countries, the figures of which range from 1.2 to $23.8 \%{ }^{27}$

The factors that increase the risk for developing ROP undoubtedly include gestational age and birth weight. In the ETROP study, ${ }^{12}$ a ROP incidence of $68 \%$ was 


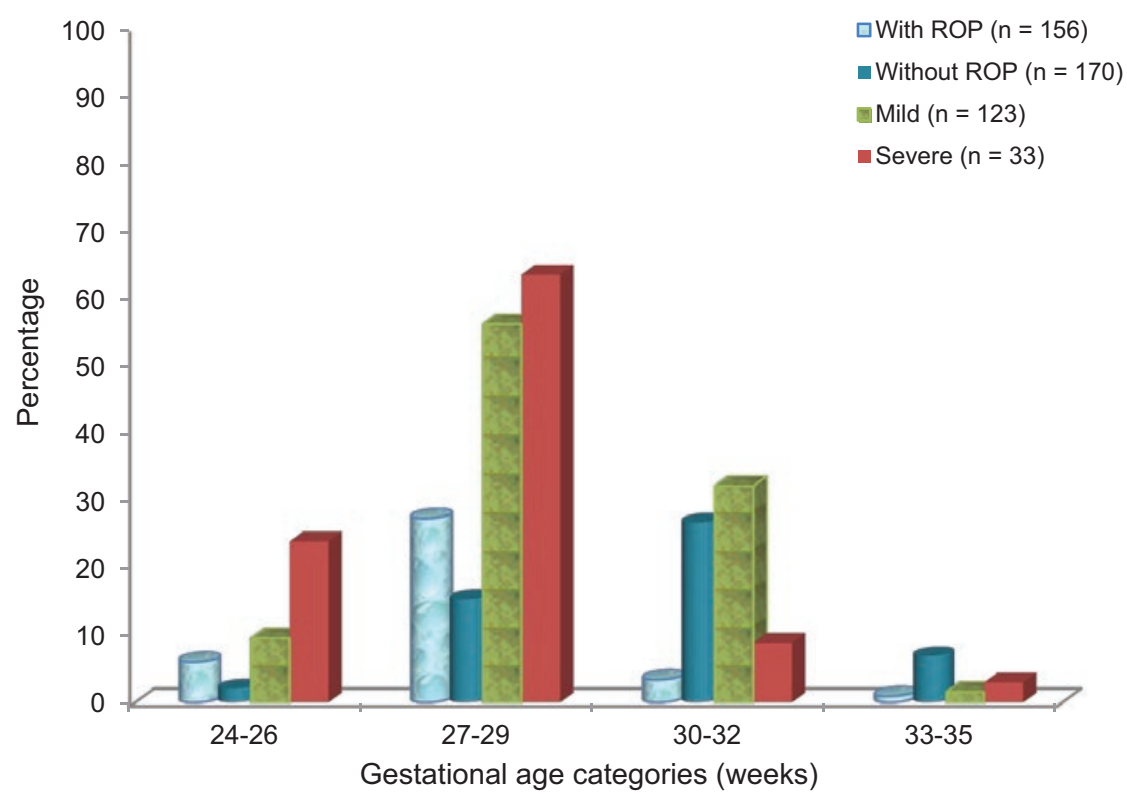

Figure 1. Retinopathy of prematurity $(R O P)$ frequency and severity according to gestational age.

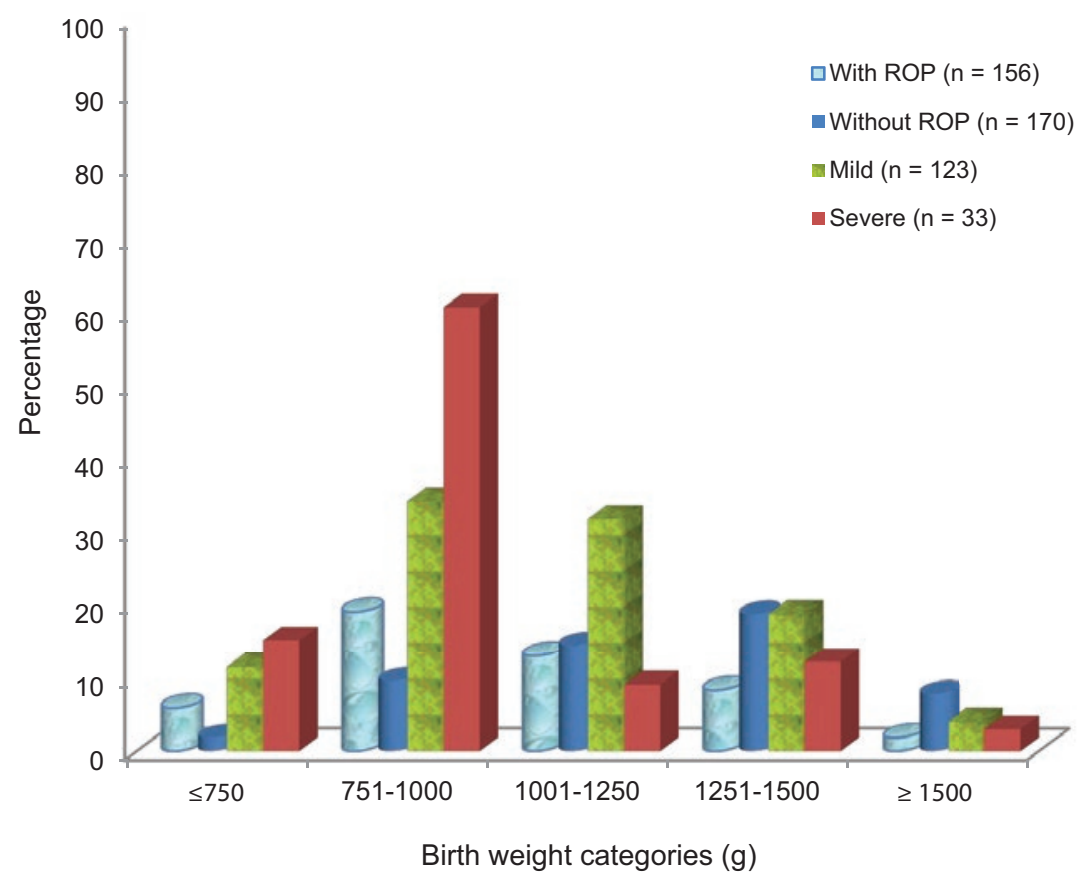

Figure 2. Retinopathy of prematurity $(R O P)$ frequency and severity according to birth weight.

reported in those under $1251 \mathrm{~g}$. In the United States, ${ }^{30}$ an incidence of $30.9 \%$ was found in children with weight between 750 and $999 \mathrm{~g}$. In the NBs analyzed in the present study, a frequency of $37.7 \%$ was found in children with weight $\leq 1250 \mathrm{~g}$ and $45.9 \%$ in those weighing $\leq 1500 \mathrm{~g}$, which is lower than that reported in India. ${ }^{31}$
Another factor that has been closely associated with the development of ROP is the use of oxygen. However, this remains controversial: in some studies, a higher incidence of ROP has been found with indiscriminate use of oxygen at high concentrations, in others this association has not been demonstrated. ${ }^{32-40}$ Nevertheless, rational use of oxygen is recommended in all premature 


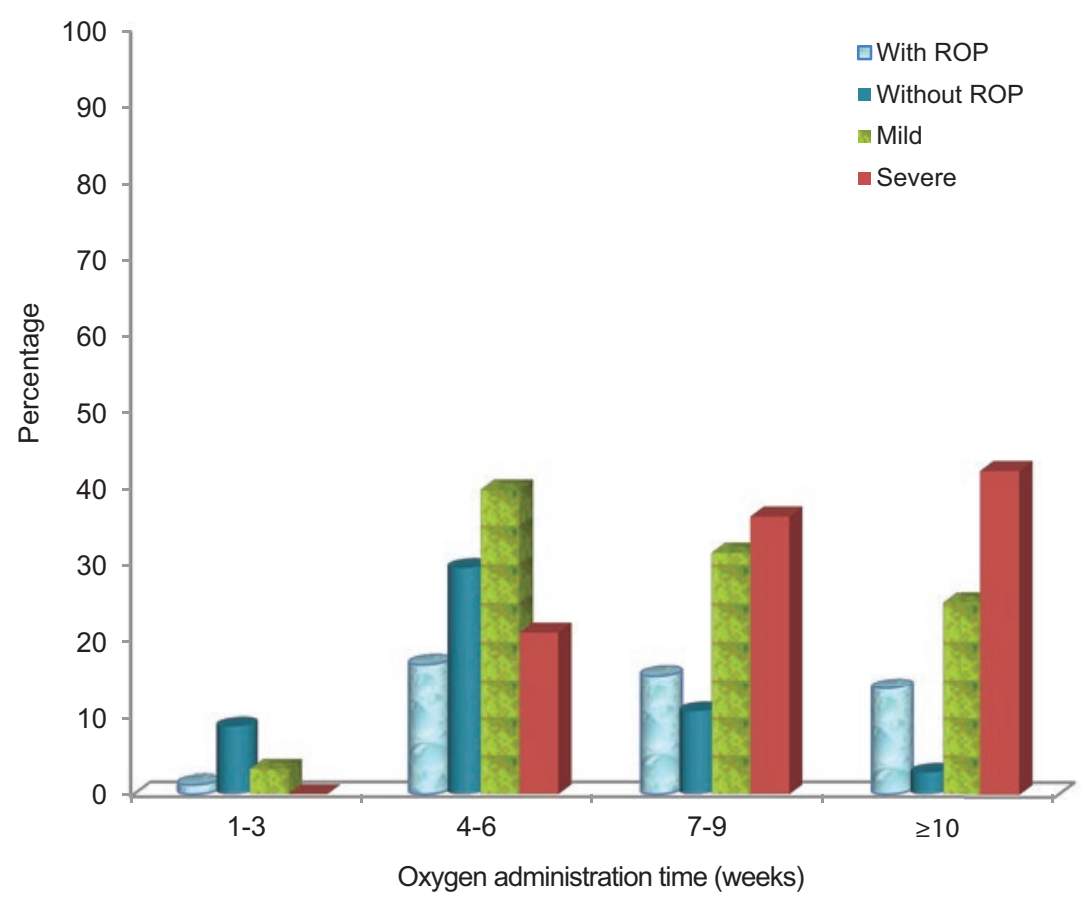

Figure 3. Retinopathy of prematurity (ROP) frequency and severity according to the time of supplementary oxygen use.

NBs, especially in the most immature. In turn, Chow ${ }^{26}$ proposes that oxygen saturations should be maintained similar to fetal levels and never higher than $95 \%$ in premature newborns. In the present research, longer oxygen usage time was found to be associated with higher ROP frequency; however, the most important is oxygen saturation reached by patients, which was information that was not possible to be obtained in this research given the design of the study and the characteristics of the hospital where it was conducted, since patients who are admitted to the NICU are referred from other hospitals with a clinical summary where oxygen concentrations used or saturations reached are not recorded, only the usage time is indicated.

All patients had one or more comorbidities, with a statistically significant difference in bronchopulmonary dysplasia and intraventricular hemorrhage, with a higher frequency being observed in children with ROP, similar to that reported by Lad. ${ }^{30}$ Patent ductus arteriosus and seizures were also found to be more common in them, with a statistically significant difference.

Given that ROP's nature is progression, and that timely treatment reduces the risk of visual loss, premature NBs with high risk should receive a careful examination by an experienced ophthalmologist, and all pediatricians and neonatologists looking after these premature infants should be aware of the implications of this pathology.

In developed countries, such as the United States and the United Kingdom, guidelines have been established for the screening of these children, but it is important taking into account that each region may have different parameters in this regard, since patient characteristics and management at NICUs are different. ${ }^{22}$ These guidelines recommend screening for children $\leq 32$ gestation weeks or with < $1500 \mathrm{~g}$ birth weight; in Mexico, technical guidelines recommend screening in NBs with gestational age $\leq 34$ weeks and birth weight $\leq 1750 \mathrm{~g} .41$

Children's first evaluation was found to have been carried out late according to international recommendations. According to the American Pediatrics Academy Ophthalmology section recommendation, ${ }^{22}$ children with 27 weeks' gestational age should be assessed at 31 weeks' postconceptional age or at 4 weeks' chronological age; in our study, children of that age were examined at between 31 and 44 weeks of postconceptional age and between 4 and 17 weeks of chronological age.

Very few patients $(20.5 \%)$ included in the present study underwent a second evaluation at the same hospital, and the interval between one and another was long. This could be due to a lack of resources to send the patients to the reference center, in addition to that in general or regional zone hospitals there are no human or technological resources for the care of these children, i.e., to establish timely and adequate diagnosis and treatment, as well as the required follow-up and rehabilitation. In a survey in pediatricians and neonatologists, Zepeda et al. ${ }^{42}$ found that the main barriers to establishing detection and effective treatment 
programs are the lack of human resources, lack of access to technology and adequate equipment, lack of financial resources and institutional support, as well as the lack of knowledge about the disease.

As regards treatment, a modality instituted in this hospital is the application of paraocular dexamethasone when ROP is detected at mild stages and, later, more advanced treatments such as cryotherapy or laser are rarely required. Owing to their anti-inflammatory properties, it is possible that steroids act as antiangiogenic agentss. This treatment is not referred to in the literature, and therefore evolution in the short, medium and long term of children to whom paraocular dexamethasone is administered remains to be analyzed.

Due to the increase in premature NBs survival, the incidence of ROP is expected to remain elevated; therefore we consider there's a need to conduct studies to identify the frequency of ROP in Mexico in order to establish opportune detection programs and thus provide them with the treatment and the corresponding follow-up.

\section{References}

1. Flynn J. Retinopathy of prematurity. En: Eichenbaum JW. Treatment of retinopathy of prematurity. EE. UU. Year Book Medical Publishers; 1990.

2. Terry TL. Extreme prematurity and fibroblastic overgrowth of persistent vascular sheath behind each crystalline lens: I. Preliminary report. Am J Opthalmol. 2018;192:xxviii.

3. Heath P. Pathology of the retinopathy of prematurity: retrolental fibroplasia. Am J Ophthalmol. 1951;34:1249-1259.

4. Gilbert C, Fielder A, Gordillo L, Quinn G, Semiglia R, Visintin P, et al. Characteristics of infants with severe retinopathy of prematurity in countries with low, moderate and high levels of development: Implication for screening programs. Pediatrics. 2005;115(5):e518-e525.

5. Manual of operations. Release 13.2. EE. UU.: Vermont Oxford Network; 2009

6. Kinsey VE, Hemphill FM. Etiology of retrolental fibroplasia and preliminary report of cooperative study of retrolental fibroplasia. Trans Am Acad Ophthalmol Otolaryngol. 1955;59:15-24.

7. Gibson DL, Sheps SB, Uh SH, Schechter MT, McCormick AQ. Retinopathy of prematurity-induced blindness: birth weight-specific survival and the new epidemic. Pediatrics. 1990;86:405-412.

8. Kinsey VE. Retrolental fibroplasia; cooperative study of retrolental fibroplasia and the use of oxygen. AMA Arch Ophthalmol. 1956;56:481-543.

9. Palmer EA, Flynn JT, Hardy RJ, Phelps DL, Phillips CL, Schaffer DB, et al. Incidence and early course of retinopathy of prematurity. The Cryotherapy for Retinopathy of Prematurity Cooperative Group. Ophthalmology. 1991;98: 1628-1640.

10. Bullard SR, Donahue SP, Feman SS, Sinatra RB, Walsh WF. The decreasing incidence and severity of retinopathy of prematurity. J AAPOS 1999;3:46-52

11. Good WV, Hardy RJ, Dobson V, Palmer EA, Phelps DL, Quintos M, et al. The incidence and course of retinopathy of prematurity: findings from the early treatment for retinopathy of prematurity study. Pediatrics. 2005;116:15-23.

12. Hoogerwerf A, Schalij-Delfos NE, Van-Schooneveld MJ, Termote JU. Incidence of retinopathy of prematurity over the last decade in the Central Netherlands. Neonatology. 2010:98:137-142.

13. Quinn GE, Barr C, Bremer D, Fellows R, Gong A, Hoffman R, et al. Changes in course of retinopathy of prematurity from 1986 to 2013: comparison of three studies in the United States. Ophthalmology. 2016; 123:1595-1600.

14. Gerull R, Brauer V, Bassler D, Laubscher B, Nelle M, Müller B, et al. Incidence of retinopathy of prematurity (ROP) and ROP treatment in Switzerland 2006-2015: a population-based analysis. Arch Dis Child Fetal Neonatal Ed. 2018;103:F337-F342.

15. Ludwig CA, Chen TA, Hernandez-Boussard T, Moshfeghi AA, Moshfeghi DM. The epidemiology of retinopathy of prematurity in the United States. Ophthalmic Surg Lasers Imaging Retina. 2017;48:553-562.

16. Park SH, Yum HR, Kim S, Lee YC. Retinopathy of prematurity in Korean infants with birthweight greater than $1500 \mathrm{~g}$. Br J Ophthalmol. 2016; 100:834-838.
17. Hernández M, Orduna C, Bosch V, Salinas R, Alcaraz JL, Marín JM. Retinopatía del prematuro en la región de Murcia (España). Incidencia y gravedad. Arch Soc Esp Oftalmol. 2008;83:423-428.

18. Cervantes-Munguía $R$, Espinosa-López L, Gómez-Contreras $P$, Hernández-Flores G, Domínguez-Rodríguez J, Bravo-Cuéllar A. Retinopatía del prematuro y estrés oxidativo. An Pediatr (Barc). 2006;64:126-131.

19. González-Urquidi O, De la-Fuente-Torres M. Incidencia de retinopatía del prematuro en el hospital Dr. Manuel Gea González. Rev Mex Oftalmol. 2004;78:1-4.

20. Sánchez E, Zapata G, Escamilla M. Retinopatía en el prematuro menor a $1500 \mathrm{gr}$ expuesto a concentraciones altas de oxígeno suplementario. Incidencia en Yucatán. Rev Mex Oftalmol. 2008;82:381-384.

21. Orozco-Gómez P, Ruiz-Morfin I, Lámbarry-Arroyo A, Morales-Cruz MV. Prevalencia de retinopatía del prematuro. 12 años de detección en el Centro Médico 20 de noviembre. Cir Ciruj. 2006;74:3-9.

22. Section on Ophthalmology American Academy of Pediatrics; American Academy of Ophthalmology; American Association for Pediatric Ophthalmology and Strabismus. Screening examination of premature infants for retinopathy of prematurity. Pediatrics. 2006;117:572-576.

23. Good WV, Early Treatment for Retinopathy of Prematurity Cooperative Group. The Early Treatment for Retinopathy of Prematurity Study; structural findings at age 2 years. Br J Ophthalmol. 2006;90:1378-1382.

24. Msall ME, Phelps DL, Hardy RJ, Dobson V, Quinn GE, Summers CG, et al. Educational and social competencies at 8 years in children with threshold retinopathy of prematurity in the CRYO-ROP multicenter study. Pediatrics. 2004;113:790-799.

25. International Committee for the Classification of Retinopathy of Prematurity. The International Classification of Retinopathy of Prematurity revisited. Arch Ophthalmol. 2005;123:991-999.

26. Chow LC, Wright KW, Sola A; CSMC Oxygen Administration Study Group. Can changes in clinical practice decrease the incidence of severe retinopathy of prematurity in very low birth weight infants? Pediatrics. 2003;111:339-345.

27. Zimmermann-Carrion J, Fortes-Filho FJB, Tartarella MB, Zin A, Dorneles-Jornada I. Prevalence of retinopathy of prematurity in Latin America. Clin Ophthalmol. 2011;5:1687-1695.

28. Binkhathlan AA, Almahmoud LA, Saleh MJ, Srungeri S. Retinopathy of prematurity in Saudi Arabia incidence, risk factors, and applicability of current screening criteria. Br J Ophthalmol. 2008;92:167-169.

29. Hameed B, Shyamanur K, Kotecha S, Manktelow B, Woodruff G, Draper ES, et al. Trends in the incidence of severe retinopathy of prematurity in a geographically defined population over a 10-year period. Pediatrics. 2004;113:1653-1657.

30. Lad EM, Hernández-Boussard T, Morton JM, Moshfeghi DM. Incidence of retinopathy of prematurity in the United States: 1997 through 2005. Am J Ophthalmol. 2009;148:451-458.

31. Vinekar A, Dogra MR, Sangtam T, Narang A, Gupta A. Retinopathy of prematurity in Asian Indian babies weighing greater than 1250 grams at birth: ten year data from a tertiary care center in a developing country. Indian J Ophthalmol. 2007;55:331-336.

32. Sola A, Chow L, Rogido M. Retinopathy of prematurity and oxygen therapy: A changing relationship. An Pediatr (Barc). 2005;62:48-63.

33. Carlo WA, Finer NN, Walsh MC, Rich W, Gantz MG, Laptook AR, et al. Target ranges of oxygen saturation in extremely preterm infants. $\mathrm{N}$ Engl J Med. 2010;362:1959-1969.

34. Bedrossian RH, Carmichael P, Ritter JA. Effect of oxygen weaning in retrolental fibroplasia. AMA Arch Ophthalmol. 1954:53:514-518.

35. Bedrossian RH, Carmichael P, Ritter J. Retinopathy of prematurity (retrolental fibroplasia) and oxygen. I. Clinical study. II. Further observations on the disease. Am J Ophthalmol. 1954;37:78-86.

36. Hittner HM, Speer ME, Rudolph AJ, Blifeld C, Chadda P, Holbein ME, et al. Retrolental fibroplasia and vitamin $E$ in the preterm infant - comparison of oral versus intramuscular: oral administration. Pediatrics. 1984:73-238-249.

37. Gaynon MW, Stevenson DK, Sunshine P, Fleisher BE, Landers MB. Supplemental oxygen may decrease progression of prethreshold disease to threshold retinopathy of prematurity. J Perinatol 1997:17:434-438.

38. Lloyd J, Askie L, Smith J, Tarnow-Mordi W. Supplemental oxygen for the treatment of prethreshold retinopathy of prematurity. Cochrane Database Syst Rev. 2003;2:CD003482.

39. Tin W, Milligan DW, Pennefather P, Hay E. Pulse oximetry, severe retinopathy, and outcome at one year in babies of less than 28 weeks gestation. Arch Dis Child Fetal Neonatal Ed. 2001;84:106-110.

40. Chen ML, Guo L, Smith LE, Dammann CE, Dammann O. High or low oxygen saturation and severe retinopathy of prematurity: a meta-analysis. Pediatrics. 2010;125:1483-1492.

41. Secretaría de Salud. Manejo de la retinopatía del recién nacido prematuro. Lineamiento técnico. México: Secretaría de Salud; 2007.

42. Zepeda-Romero LC, Gutiérrez-Padilla JA, De la Fuente-Torres MA, Angulo-Castellanos E, Ramos-Padilla E, Quinn GE. Detection and treatment for retinopathy of prematurity in Mexico: need for effective programs. J AAPOS. 2008:12:225-226. 